\title{
LA DIVULGACIÓN DE LA TOMA DE GRANADA: OBJETIVOS, MECANISMOS Y AGENTES
}

\author{
THE CONQUEST OF GRANADA AND PROPAGANDA SPREADING: \\ OBJECTIVES, MECHANISMS AND AGENTS
}

\section{Ma DOLORES RiNCón GONZÁlEZ Universidad de Jaén}

\begin{abstract}
Resumen: Bajo la supervisión y estímulo de los protonotarios, Bernardino López de Carvajal y Juan Ruiz de Medina, el éxito final de las campañas contra los moros de Granada fue divulgado desde la corte papal al resto de Europa. La lectura de dos sumarios latinos y el cotejo con el texto preliminar de un incunable francés prueban el papel desarrollado por ambos personajes en la exaltación propagandística de Fernando el Católico.
\end{abstract}

Palabras clave: 1492 . Toma de Granada. Difusión propagandística; Relaciones internacionales; Italia española; Protonotarios: Bernardino López de Carvajal, Juan Ruiz de Medina. Jerónimo Münzer. Harmann Schedel.

\begin{abstract}
Under the supervision and stimulus of proto-notaries Bernardino López de Carvajal and Juan Ruiz de Medina, the news of the successful end to war against Moorish Granada spread far and wide from the Papal court to the rest of Europe. The reading of two Latin summaries and the comparison with the preliminary text of a French incunabulum show the importance of both figures in the exalting propaganda of Ferdinand the Catholic.
\end{abstract}

Keywords: Conquest of Granada; Propaganda spreading; Internatinal relations; Spanish Italy; Chiel notaries/Proto-notaries Bernardino López de Carvajal, Juan Ruiz de Medina, Jerónimo Münzer, Harmann Schedel.

\section{SUMARIO}

1. Introducción.- 2. La victoria sobre Granada en su contexto europeo.- 3. Sumarios Latinos sobre la toma de Granada.- 3. Incunables franceses y la actividad de los embajadores españoles en Roma.

\section{INTRODUCCIÓN}

Desde las últimas campañas de la Guerra de Granada, fueron abundantes y diversos los mecanismos que se utilizaron para divulgar por las cortes europeas el desarrollo y desenlace de los acontecimientos acaecidos a finales del siglo XV. El instrumental puesto en juego fue implementado y orquestado en buena parte desde la ciudad de Roma. 
La preocupación, el empeño por dar a conocer lo que sucedía en el Sur de la península ibérica guardaba estrecha relación con intereses perseguidos por los reinos de España y también, de manera más particularizada, por los Borja; circunstancias que contaron con un apoyo importante por parte de grupos hispanófilos en Roma.

Este esfuerzo por dar a conocer los acontecimientos españoles, basado en un claro interés propagandístico, se benefició de la inquietud, más o menos generalizada, por la situación de los territorios cristianos ante el avance de los turcos; preocupación que había llegado a ser un tema muy importante en la política papal de manera que la llamada a la Cruzada estaba omnipresente y los discursos contra el común enemigo se convirtieron en ejercicios retóricos habituales. La guerra contra los turcos se presentaba como necesaria para poder vivir en paz ${ }^{1}$. Era además considerada una "guerra justa" pues detrás de ella estaba la defensa de la Cristiandad y, en consecuencia, de los territorios cristianos. Con todo, aquel sentimiento de peligro y sus ardorosas manifestaciones no llegaron a traducirse en empresas bélicas comunes como sugería la alusión a la Cruzada. Ante el fracaso, en este sentido, de todos los empeños, la caída de Granada se magnificó e interpretó como la compensación por la pérdida de Constantinopla. El éxito de los españoles tras años de campañas resultó un feliz ejemplo y acicate; de hecho con anterioridad a la caída del reino nazarí, españoles y portugueses eran puestos como modelos en su lucha contra los infieles; el mismo Aeneas Silvio antes de ser Papa (Pío II) lo reconocía con estas palabras:

"Muchos son los reyes de España y diferentes en poderío, régimen, en voluntad y en opinión; desde el extremo occidental no hay que arrastrarlos hasta el Septentrión y además tienen la guerra en casa contra los granadinos"2.

Cabe también suponer que Pomponio Leto recogía el sentir de muchos cuando afirmaba de manera rotunda que únicamente Fernando el Católico había llevado a su fin una guerra justa ${ }^{3}$.

Todas estas circunstancias propiciaron un ambiente proclive al tema y explican, en gran medida, el llamativo aparato de divulgación aplicado a la noticia del final del reino nazarí y la correspondiente recepción en cortes y círculos europeos, de manera especial en Roma, y aunque tales procedimientos no serían inusuales, sin embargo, lo que los hace especialmente destacables, en el caso de la toma de Granada, fue la abundancia de recursos escritos

\footnotetext{
${ }^{1}$ Resulta elocuente en este sentido la actitud del Cardenal Bessarion cuando exponía: "Bellum gerendum est ut in pace vivamus. Si bellum omittamus, pacem habemus nullam"; en efecto, se condicionaba la paz a la guerra; una guerra considerada justa por muchos humanistas. El concepto de "guerra justa", fue defendido, entre otros, por el español Rodrigo Sánchez de Arévalo.

${ }^{2}$ Cf. Llorca García, Villoslada Montalbán, Historia de la Iglesia Católica, Madrid $1967, \mathrm{III}^{2}, \mathrm{p}_{\dot{L}}$ 357. Sobre la representación del turco en el arte italiano renacentista $v d$. Sabine POESCHEL, $\dot{L}$ 'Orientalismo e l'idea della pace in Roma di fronte all'Europa al tempo di Alessandro VI, III (M. CHIABO; S. MADDALO; M. Miglio; A.M. OlIVA), Roma, 2001, pp. 803819.

${ }^{3}$ POMPONIO LETO: "Iusta arma nostro saeculo (...) unus Ferdinandus rex Hispaniarum movit, cuius ingenita virtus, divinitus adiuta, victis, fugatis, partim caesis et partim sub iugum actis hostibus palmam divinae et inmortalis gloriae invenit". ( $c f$. W. ZABUGHIN, G. Pomponio Leto, Roma, 1909, I, p. 229)
} 
con gran variedad de formas literarias ${ }^{4}$, así como la rapidez de su circulación, debida, entre otras razones, al uso de la imprenta.

Papel destacado y muy significativo en todo el proceso de difusión fue el desempeñado desde Roma por los embajadores españoles Bernardino López de Carvajal y Juan Ruiz de Medina como evidencia el texto francés de los incunables, al que nos referiremos más adelante, o la praefatio del drama de los Verardi, Fernandus servatus ${ }^{5}$, por citar algunas fuentes.

\section{LA VICTORIA SOBRE GRANADA EN SU CONTEXTO EUROPEO}

Puede resultar reiterativa la alusión a la resonancia en Europa del final de reino nazarí de Granada. Se trata de un asunto ya conocido y al que nos hemos referido en algunas ocasiones ${ }^{6}$. Sin embargo, la atención que se le prestó fue de una envergadura tal que todavía, con el distanciamiento y la objetividad que nos debería brindar el tiempo, nos sigue pareciendo desproporcionada si la comparamos con acontecimientos de idéntico calado, o de repercusiones históricas de una magnitud que no admite comparación con el suceso granadino si se toman en cuenta sus repercusiones en el curso de la historia de la humanidad e incluso de la vida en el planeta. Los viajes de Colón fueron un acontecimiento prácticamente simultáneo a la caída de Granada, pero comparado con el asunto granadino, cabe afirmar que fue presentado en una escala que al poco tiempo ya se mostraba inadecuada. Posiblemente presentar el éxito colombino como un suceso secundario no se basó en una auténtica convicción: entraban en juego muchos intereses y, sin lugar a dudas, se actúo en consecuencia y con la rapidez que requerían las circunstancias. Así lo confirma el papel que jugó la celebérrima carta de Colón, la prontitud de su divulgación, las traducciones citato equo, la lluvia de ediciones de incunables, y por supuesto el vaivén y sucesión de las famosas Bulas Alejandrinas ${ }^{7}$. En aquel momento se tuvo más o menos conciencia del calado político y económico del descubrimiento aunque la fructífera crisis de las mentalidades, la emancipación del pensamiento, los cuestionamientos de la moral, de la teología..., que señalarían para siempre una nueva época, irían tomando forma a buen ritmo aunque no tan acelerado.

Aquel admirabilis annus 1492, en el que la historia de España marcó por un momento el ritmo de la de todos, se ha presentado frecuentemente como la fecha de una unificación múltiple. En el aspecto religioso, se subraya

${ }^{4} \mathrm{G}$. CARLO RosSI, I Re Cattolici in testimonianze letterarie e storiche italiane del tempo, "V Congreso de Historia de la Corona de Aragón", I, Zaragoza, 1955, pp. 47-72.

${ }^{5}$ Marcelino VERARDI, Fernandus servatus, Roma, 1493.

${ }^{6} \mathrm{M}^{\mathrm{a}}$ Dolores RINCÓN GonZÁLEZ, Presenza dell'elemento italiano nella stampa di libri spagnoli o di tematica spagnola in tipografie tedesche del XV secolo o degli inizi del XVI, "IX International Congress of Neo-Latin Studies", Bari, 1994, pp. 509-515.

${ }^{7}$ M.D. RINCón, La divulgación de la Toma de Granada y el Descubrimiento de América. Una edición de Basilea de 1494 , en El Reino De Granada y el Nuevo Mundo, "V Congreso Internacional de Historia de Ảmérica”, Granada, 1992, pp. 29-39. 
esa unidad a partir del decreto de expulsión de los judíos y la anexión de Granada. Contrariamente la expulsión de los judíos comparada con el caso de Granada apenas si trascendió a los textos fuera del ámbito territorial hispano, a pesar de ser frecuentes las quejas de los Reyes Católicos sobre la acogida de los sefardíes en Roma. Las razones de este contraste pueden ser varias, pero sin duda pesó en la situación el que los judíos no formaron un grupo étnico radicalmente marcado y resultaba fácil confundir cristianos y judíos en muchos aspectos externos; las diferencias estaban básicamente centradas en la práctica religiosa y en determinados aspectos que podían pasar desapercibidos.

Por el contrario, la toma de Granada sí tuvo una resonancia inmediata considerable y prácticamente simultánea al acontecimiento, lo que no dejaría de sorprendernos si no se atiende a los motivos de aquel despliegue de recursos para divulgar la noticia. A la profusión de escritos, de parlamentos, de discursos, representaciones dramáticas se añadió una enérgica actividad impresora que facilitó su difusión en vernáculo, pero sobre todo en latín como lengua franca.

También el enlazar el tema de Granada con un atentado sufrido por el Rey Fernando en Barcelona sirvió para reforzar los objetivos que se perseguían con la constante alusión al éxito en Granada. En diciembre de 1492 un "loco imaginativo", fracasaba en su intento de regicidio ${ }^{8}$ y con la llegada de la noticia a Roma volvieron a ponerse en marcha todos los mecanismos de divulgación con los que se había contado pocos meses antes. Pronto, aquel suceso sin apenas consecuencias, quedaría relegado al capítulo de las anécdotas aunque en principio se atribuyó la acción a un payés de remensa y esta sospecha desvela cierta inquietud por un trasfondo conflictivo en el Reino de Aragón. En cualquier caso, al tema de la toma de Granada se unió en alguna edición romana ${ }^{9}$ el atentado de Barcelona con la finalidad más o menos manifiesta de exaltar la figura de Fernando II de Aragón y su carácter mesiánico ${ }^{10}$.

\footnotetext{
${ }^{8}$ Rúbriques de Brúniquer. Ceremonial dels Magnifichs Consellers y Regiment de la Ciutat de Barcelona. [7diciembre 1492] "A 7 de Desembre 1492, succehí lo cas de la coltellada del Rey Dn. Fernando. Devallant dit senyor per la scala del Palau, feu lo invasor un pages de Canyamás foll y orat, y los consellers anaven a visitarlo cada dia, com se veu en un Consell celebrat a 13 de dit, y com se scriu ab cartas de consellers a 9 y 14 de desembre als Gerona y de Tortosa" (cf. J. Angel SESMA MUÑOZ, Los Idus de diciembre de Fernando II. El atentado de Rey de Aragón en Barcelona, Zaragoza, 2006).

${ }^{9}$ M.D. Rincón, Historia Baetica de Carlo Verardi. Drama humanístico sobre la Toma de Granada. Granada, 1992; este drama conoció seis ediciones de incunables; en tres de ellas (Roma 1493 b. Salamanca 1494 y Valladolid 1497) va acompañado de la pieza dramática sobre el atentado de Barcelona, Fernandus servatus. Un repaso por el catálogo de la imprenta romana de Eucharius Silber da buena cuenta de la abundancia de textos impresos relacionados con la actualidad española (y. Paola FARENGA, La edizioni di Eucario Silber en Roma di fronte all'Europa al tempo di Alessandro VI, Roma, 2001, II, pp. 428-430).

${ }^{10}$ M.D. RINCóN, Discite nunc igitur, reges, aeterna mereri nomina: Una interpretación del atentado de Barcelona de 1492, "De orbis hispani linguis litteris historia moribus", Frankfurt am Main, 1994, pp. 567-576. Ana Isabel CARRASCO MANCHADO, Propaganda política en los panegíricos de los Reyes Católicos. Una aproximación, "Anuario de Estudios Medievales" 25, 2 (995), pp. 517-544. En 1497 con motivo de la muerte del príncipe D. Juan, Roma volvió a contemplar y oír de nuevo todo un despliegue de celebraciones de las que la imprenta volvió a dejar constancia. Sobre los funerales del Príncipe en Roma $v d$. Manuel VAQUERO PIÑERO, I
} 
En suma, cabría afirmar que las circunstancias e intereses que propiciaron y fomentaron la resonancia de la caída de Granada en manos de los cristianos fueron de índole diversa.

En efecto, la inquietud creada en el centro de Europa e Italia como consecuencia de la caída de Constantinopla en 1453 y el ataque a Belgrado en 1456 tras su conquista en 1521, alentó el entusiasmo suscitado por la victoria de los españoles. El hecho de compartir unas mismas creencias religiosas englobaba a moros y turcos como enemigos comunes y los hacía formar parte del "otro" cultural y religioso; los homogeneizaba en la extrañeza de su alteridad. Esta circunstancia conducía a la suposición de alianzas y ayudas mutuas, si bien, la relación entre nazaríes y otomanos resultó prácticamente inexistente aunque en diferentes textos literarios aparezcan como aliados.

Es además sabido que la legitimidad del Sacro Imperio RomanoGermánico estaba basada en la misión específica de la defensa de la Cristiandad. La denominada cuestión turca (Turkefrage) era un tema importante dentro de la política imperial. Presentar la conquista del Reino de Granada como una cruzada en defensa de la expansión de la Cristiandad era una excelente carta de presentación para una monarquía católica con vocación de liderazgo entre las potencias europeas y con aspiraciones, por tanto, a sostener la corona imperial en un plazo relativamente corto y, por ende, aspirante también al dominio en Italia ${ }^{11}$ para lo cual era importante mantener una relación privilegiada con el Papa. Redunda en esto el hecho de que los españoles, como consecuencia de la guerra contra los musulmanes, disfrutaran de Bula de Cruzada; precisamente entre los documentos estudiados del fondo Schedel de la Bayerische StaatsBibliothek de Munich (BSB) se halla una copia del texto de la que Inocencio VIII concedió a los españoles por su lucha contra los granadinos.

También la presencia y cometido de Jerónimo Münzer en calidad de enviado de Maximiliano I de Austria en España en 1494 es prueba del interés del propio emperador por tener conocimiento verídico y fiable de la nueva situación en la península.

Por otra parte, si nos centramos en Roma, caput Mundi, el final de la Reconquista coincide con el punto culminante de las relaciones entre España y Roma, relaciones con una intensidad desconocida en épocas anteriores ${ }^{12}$. Cada uno de los éxitos españoles en el reino de Granada fue bien acogido y aún mejor utilizado por los grupos hispanófilos encabezados por los Riarios

funerali romani del principe Giovanni e della regina Isabella di Castiglia: rituale politico al servizio della monarquia spagnola en Roma di fronte all'Europa al tempo di Alessandro VI, Roma, 2001, II, pp. 641-655.

${ }^{11} \mathrm{~A}$. KOHLER, La doble boda de 1496/1497. Planteamientos, ejecución y consecuencias dinásticas en Reyes y Mecenas. Los reyes Catolicos-Maximiliano y y los inicios de la Casa de Austria en España, Milán, 1992, pp. 253-272; El Sacro Imperio Romano en la época de Maximiliano en Roma di fronte all 'Europa al tempo di Alessandro VI, Roma, 2001, I, pp.77-84.

${ }^{12}$ Maria Antonietta VISCHEGLIA, Convergencia y conflictos. La Monarquia católica y la Santa Sede (Siglos XV-XVIII) "Studia historica. Historia moderna", 26 (2004), p. 156. A. SERIO, Modi, tempi e uomii della presenza hispana a Roma tra la fine del Quattrocento e il primo Cinquecento (1492-1527) en L'Italia di Carlo $V$. Guerra, religione e politica nel primo Cinquecento (F. CANTÚ; M. A. VISCHEGLIA, eds.) Roma, 2003, pp. 433-376. 
y, de forma especial, por el círculo en torno al cardenal Rodrigo Borja, entonces con las miras puestas en la Cátedra de Pedro.

Rodrigo Borja, junto con Bernardino López de Carvajal ${ }^{13}$, Juan Ruiz de Medina (obispos de Badajoz y Astorga) y el cardenal Rafael Riario, fue uno de los principales patrocinadores de festejos y celebraciones por la victoria sobre los granadinos ${ }^{14}$ : festejos variados, populares o aúlicos, religiosos y lúdicos, entre los que no faltaron las corridas de toros con un diestro Vicecanciller Borja interviniendo en la lidia. Con todo ello las aspiraciones de los Borjas, con la colaboración de españoles y allegados, desencadenaron una activa labor de captación y propaganda que desembocó con éxito el 11 de agosto de 1492 en la coronación del valenciano como Papa Alejandro VI. La utilización del asunto granadino incluso fue más allá de los mecanismos que favorecieron su aspiración al papado. En este sentido es, tal vez, sutil la representación del Arco de Constantino en un fresco de la Sala dei Santi de las estancias vaticanas. El monumento aparece rematado por el toro borgiano y con la inscripción CVLTOR PACIS. En aquel fresco se representa la Disputa di S. Catarina con personajes identificables por su atuendo como $\operatorname{turcos}^{15}$.

Por último una nueva motivación alentó la campaña de exaltación del rey español. Apenas había transcurrido un año desde los acontecimientos de Granada, cuando se hizo manifiesto el enfrentamiento entre portugueses y españoles en el reparto de las tierras aún no descubiertas. Aquel enfrentamiento concluiría en el Tratado de Tordesillas (7-6-1494) después de la promulgación de las famosas Bulas Alejandrinas, otorgadas entre mayo y septiembre de 1493 coincidiendo con la edición en Roma de una secuencia de incunables relacionados con Granada y, en algún caso, con el atentado en Barcelona.

Expuestas estas consideraciones, cobra aún mayor interés el contenido de dos sumarios latinos y su correspondiente traducción francesa, ya que ofrecen una precisa información sobre la importante implicación de los embajadores españoles en Roma en las tareas de divulgación de la toma de Granada.

Entre la abundancia de textos en diferente formato y con diverso soporte, ya sean misivas, discursos o composiciones literarias de distintos géneros, etc., se hallan varios sumarios latinos que recogen las últimas campañas en el cerco de Granada. Dos copias manuscritas de un mismo texto se encuentran en el fondo Hartmann Schedel de la Biblioteca del Estado de Baviera y se corresponden como texto base con traducciones a diferentes lenguas romances, concretamente al italiano y al francés. El texto francés está recogido en dos incunables franceses de la Bibliothèque nationale de París

\footnotetext{
${ }^{13}$ G. Fragnito, Carvajal Bernardino López, en Dizionario Biografico degli Italiani (DBI) 21, Roma, 1978, pp 28-34; José GoÑ, López de Carvajal, Bernardino en:), Diccionario de Historia Eclesiástica de España (Quintín ALDEA VAQUERO; Tomás MARÍN MARTIINEZ; José VIVES GATELL drs.) Suplemento 1, Madrid, 1987, pp. 442-450.

${ }^{14}$ Fabrizio CRUCIANI, Feste per la conquista di Granata en Teatro nel Rinascimento Roma 1450-1550, Roma, 1983.

${ }^{15}$ S. POESCHEL, o. $c$., pp. 812 y 816.
} 
$(\mathrm{BnF})$. En su preliminar el traductor nos brinda una información preciosa acerca de los procedimientos utilizados para la difusión de los acontecimientos $\mathrm{y}$ sus agentes.

El texto de los sumarios y el de los incunables no suponen, intrínsecamente en sus contenidos, una aportación nueva y significativa en datos, pero sí que añaden de forma precisa argumentos y pruebas sobre el modo como se trasladó la noticia a toda Europa, los personajes que se hallaron implicados en tal proceso, y los intereses más o menos particulares con que actuaron. Los personajes citados explícitamentes son los protonotarios Bernardino López de Carvajal y Juan Ruiz de Medina.

\section{LOS SUMARIOS LATINOS SOBRE LA TOMA DE GRANADA}

Los Sumarios Latinos, a los que nos referimos, forman parte de sendos códices del Fondo Schedel de la Biblioteca del Estado de Baviera en Munich (BSB). En general, en este fondo se integran documentos de temática diversa, así junto a tratados gramaticales, hallamos de lógica, retórica, matemáticas, filosofía, composiciones literarias, etc. Entre esta diversidad, los relacionados con temas españoles ocupan un espacio apreciable. Naturalmente si tenemos en cuenta la naturaleza miscelánea del fondo, es fácil suponer que no hubo una motivación uniforme o única en el proceso de su compendio. Repasando los índices y atendiendo a la personalidad del compilador, se puede decir que en unos casos imperaron razones de carácter literario, en otros científicas, políticas, de circunstancias, etc. Esta apreciación es aplicable al conjunto de materiales que guardan relación con España.

Para justificar este supuesto es preciso considerar ciertos aspectos prosopográficos del médico y humanista de Núremberg, Hartmann Schedel (1440-1514), que ponen de manifiesto sus intereses más o menos directos, más o menos uniformes, por temas relacionados con España.

Hartmann Schedel, maestro en Artes, doctor médico, humanista, bibliófilo, cronista, estudió en Leipzig entre 1463 y 1466, en aquel año se trasladó a Padua para doctorarse en Medicina. Durante su estancia en Italia entró en contacto con intelectuales italianos y de allí debió de arrancar, sin duda, su interés por la comedia humanística entonces en boga en Italia. Esta circunstancia justifica la existencia de una copia manuscrita de la Historia Baetica, drama de los Verardi sobre la toma de Granada compuesto antes del 21 de abril de 1492 y que aparece recogido en Clm 428 de la BSB de Munich $^{16}$. La copia fue realizada por el propio Schedel en 1494 como puede leerse en el colofón en donde el copista se identifica mientras atiende a los contagiados por la peste (Scripsi ego Hartmannus Schedel [...] peste nondum cessante). En el campo meramente literario el drama de los Verardi atrajo el interés de un público interesado por las nuevas formas dramáticas y no sólo

${ }^{16}$ Este hecho unido al conocimiento que Jacob Locher (Philomosus) desvela del citado drama de Verardi, sitúa a la Historia Baetica como uno de los puntos de arranque del teatro alemán. 
Schedel lo copiaba mientras atendía a los contagiados por la peste, también Jacob Locher introdujo en Alemania la pieza. Es perceptible la presencia del drama de Verardi en el diálogo en cinco actos titulado Historia de rege Franciae escrito por Locher, como un dato más que nos ayuda a constatar la incidencia de la Historia Baetica en la incipiente literatura escénica alemana.

En el año 1470 Schedel se hallaba instalado en Núremberg en donde ejerció la medicina y preparó la conocida Weltkronik o Liber Cronicorum editada en $1493^{17}$ por el impresor Anton Koberger. La composición de una obra tan extensa sólo fue posible gracias a su sorprendente biblioteca privada, que como hemos indicado se conserva, en gran medida, en la biblioteca de Munich ${ }^{18}$.

Colaborador en la composición de la Crónica fue Jerónimo Münzer o Monetario. Los contactos y la amistad de ambos posiblemente arranquen de su estancia en la universidad de Leipzig entre los años 1464 y 1476. Algunos aspectos más de sus respectivas biografías coinciden: Monetario también vivió un tiempo en Italia en donde se doctoro en Medicina (Pavia 1476), más tarde vivió en la ciudad de Núremberg en donde llegó a conseguir la ciudadanía (1484). Un dato importante común a ambos fue su interés por la bibliofilia ${ }^{19}$ y por determinados temas. Precisamente del relato original de J. Münzer, Itinerarium siue peregrinatio excellentissimi viri artium ac utriusque medicine doctoris Hieronimi Monetarii de Feltkirchen ciuis Nurembergensis ${ }^{20}$ sólo se conserva una copia manuscrita en el mismo fondo de la BSB (Clm 431, fol. 96-274v. $)^{21}$. Con respecto a Granada, la descripción que hizo el viajero, es, sin lugar a dudas, insustituible a la hora de conocer la situación de la ciudad y del reino de Granada en el año 1494. El Itinerarium sive peregrinatio de Münzer no es un simple libro de viajes al uso de la época como podemos deducir del título completo. Se trata más bien de las notas precisas de alguien que cumple con una misión y el encargo de observar y trasmitir con precisión aspectos previamente determinados. El libro de Münzer cumplió ese cometido

\footnotetext{
${ }^{17}$ Christoph RESKE, Die Produktion der Schedelschen Weltchronik in Nürnberg, Wiesbaden, 2000. Stephan FüSSEL, Chronicle of the World, Koln, 2001.

${ }^{18} \mathrm{El}$ resto de la biblioteca está repartida entre la fundación Fugger, la biblioteca central de Baviera (Bayerische Staatsbibliothek) y Londres, Nueva York, Praga o Hamburgo. Elisabeth RÜCKER, Hartmann Schedels Weltchronik - Das grösste Buchunternehmen der Dürer-Zeit, München, 1988.

${ }^{19}$ Ernst Philip GOLDSCHMIDT, Hieronymus Münzer und seine Bibliothek, Londres, 1938.

${ }^{20}$ Albrecht CLASSEN, Die iberische Halbinsel aus der Sicht eines humanistischen Nürnberger Gelehrten. Hieronymus Münzer, Itinerarium Hispanicum (1494-1495), Instituto de investigaciones histórica de Austria, Viena, 2003. Klaus HERBERS, Die ganze Hispania. Der Nürnberger Hieronymus Münzer unterwegs, seine Ziele und Wahrnehmung auf der Iberischen Halbinsel (1494-1495) en Grand Tour. Adeliges Reisen und europäische Kultur vom 14. bis zum 18. Jahrhundert (Rainer BABEL, Werner PARAVICINI, Hrsg.), Ostfildern, 2005, pp. 293-308.

${ }^{21}$ Hoy se encuentran algunas partes del libro traducidas en los idiomas de los países visitados (español, portugués...). Pero en la mayor parte de los casos se trata de traducciones parciales. También existe una edición comentada en latín y actualmente la Universidad Friedrich-Alexander de Erlangen-Núremberg elabora otra edición con comentarios y la traducción alemana. El texto fue publicado por Ludwig PFANDL, Itinerarium hispanicum Hieronymi Monetarii 1494-1495. "Revue Hispanique" 48 (1920). CAMACHO EVANGELISTA hizo una traduçción parcial de lo referente a Granada. Existe también una traducción española reciente, Jerónimo MÜNZER Viaje por España y Portugal, Madrid 2002.
} 
y nos ha llegado como uno de los testimonios más directos y calificados de la situación de la ciudad tras la toma.

En el relato del viaje también se incluyen noticias sobre los nuevos descubrimientos. Conocidos son los contactos de Münzer con Juan II de Portugal. Su recorrido por el sur de España (Sevilla en concreto) en 1494 le permitió ver a los indios traídos por Colón, e incluso entró en contacto con el padre Bernardo Boil, acompañante del almirante en su segundo viaje. Por estas razones, Münzer ofrece también uno de los primeros testimonios sobre América. Es lógico pensar que su relato sobre el descubrimiento debió de ser rico en informaciones sobre el tema americano, pero tanto éste, como otros trabajos de astronomía o el mapa original de Alemania se han perdido. Afortunadamente una copia de la Carta de Alemania inferior aparece entre los grabados de la crónica de Schedel.

Desde las últimas campañas de la Guerra de Granada, los mecanismos de divulgación de los acontecimientos se sucedieron por toda Europa de una manera cada vez más abundante y frecuente. Como hemos indicado anteriormente, a los intereses perseguidos por los reinos de España se unía una inquietud generalizada sobre la situación de los territorios cristianos frente al avance de los turcos. Examinar la actividad de protonotarios, embajadores, obispos en torno al papa o al emperador nos acerca al tema y a la inquietud creciente ante el avance otomano. En general, en los textos que estudiamos no se señalan diferencias entre turcos y musulmanes españoles; al contrario, se les representa como a un enemigo común compacto y opuesto a los cristianos, a quienes también se representan aglutinados bajo el mismo signo religioso, de manera que cada victoria sobre los granadinos era celebraba como un triunfo de todos los cristianos y, por parte de Roma, servía de referencia modélica para el resto de los príncipes cristianos con la finalidad de animar a una nueva cruzada. Qué duda cabe que estas circunstancias favorecieron y fomentaron la divulgación del final del reino nazarí y la acogida de la noticia en cortes y círculos europeos. El fondo Schedel de Munich es rico, de forma específica, en noticias sobre la contienda. En él se encuentran recogidos dos epítomes de Diego de Muros, Rerum apud Malacam gestarum ${ }^{22}$ y la carta De Victoria Serenissimi Regis hispaniarum contra Mauros granatenses. Anno $L X X X V I I I^{23}$ en donde queda relatada la victoria sobre las ciudades de Guadix y Baza. De temática afín es el discurso de Antonio Geraldini en nombre de los Reyes Católicos ante Inocencio VIII, en donde se insiste en la alusión a la contienda granadina aún no concluida ${ }^{24}$. Al conjunto se une una recopilación de discursos.

Las noticias sobre la toma de Granada resultaron un recurso muy oportuno para situaciones diferentes. Como hemos indicado más arriba, en

\footnotetext{
${ }^{22}$ Breve Epithoma Rerum apud Malacam gestarum. Anno MCCCC.LXXXVII. BSB, Clm. 461, ff. $71 \mathrm{r}-77 \mathrm{r}$.

${ }^{23}$ De victoria serenissimi regis hispaniarum contra Mauros granatenses. Anno LXXXVIII. BSB Clm. 461, ff. $78 \mathrm{r}-84 \mathrm{v}$.

${ }^{24}$ Oratio Antonii Geraldini prothonotarii apostolicii... BSB, Clm. 461, ff. 84 r - 92 v.
} 
Roma no sólo sirvió como acicate, sin éxito, en el intento de promover una cruzada, también brindó utilidad al aspirante a la cátedra de Pedro, el aragonés Rodrigo Borja.

Y cómo no, la exaltación del acontecimiento benefició la propaganda española en Italia. En el caso de Centro-Europa, el tema ofrecía interés en la medida que respondía a las expectativas del emperador en su lucha contra el turco; de hecho, algunos de los textos referidos a Granada aparecen incluidos también dentro de compendios de obras referidas al tema turco, por ejemplo, la colección reunida por Robertus Monachus Bellum christianorum principum praecipue Gallorum contra Saracenos, publicada en Basilea en 1533. En cierta medida, los materiales bibliográficos de H. Schedel están en consonancia con esto, aunque no de manera exclusiva; puede servir como ejemplo la copia del discurso del obispo de Cesena, como tantos preocupado por la convocatoria de una nueva cruzada, discurso en el que la alusión al caso hispano se utiliza de nuevo como speculum para el resto de los príncipes cristianos. En realidad, todo eran oportunidades en las políticas nacionales o particulares.

También de forma general, se puede afirmar que los materiales de fondo Schedel tienen una estrecha correspondencia con una abundante actividad impresora al respecto tanto en Italia, como en los estados del Sur de Alemania. El estudio de tal actividad viene a confirmar los mecanismos que se utilizaron para dar a conocer el evento por las cortes europeas. En este sentido las piezas más elocuentes son los Sumarios de fondo Schedel y el texto de los incunables franceses.

Es sabido que cada paso de la contienda fue seguido en Roma a través de informes oficiales, misivas protocolarias o cartas privadas, y relaciones de todo tipo. Se conservan algunas de tales misivas de carácter protocolario y diplomático como la de Antonio Geraldini o la de López de Haro, esta última en el Archivo Segreto Vaticano. Entre las dirigidas a particulares cabe destacar las contenidas en el epistolario de Pedro Mártir, un auténtico diario de campaña escrito en la Vega granadina.

En el caso que nos ocupa el mecanismo utilizado fue como sigue. A partir de comunicados oficiales o misivas privadas, los protonotarios de los Reyes Católicos, Bernardino López de Carvajal y Juan Ruiz de Medina, compusieron los correspondientes informes oficiales. En el incipit de los sumarios de Schedel así se menciona, e incluso en el contenido en el Clm 461, fol. 273r, de forma expresa, se indica que tales embajadores eran los obispos de Badajoz y Astorga ${ }^{25}$.

La labor diplomática de ambos obispos fue muy activa en Roma. Parte de esa labor estuvo relacionada con la divulgación de los escritos, entre los que cabe destacar incluso una serie de discursos realmente pronunciados y que inmediatamente fueron encomendados a la imprenta como ocurrió con el

\footnotetext{
25 "Summa eorum quae in diversis litteris et datis scripta (dominis pacensi et Astoricensi Episcopis) Oratoribus christianissimorum ac serenissimorum Regis et Reginae Hispaniae De victoria civitatis Granatae... sunt sedecima Ianuarii $92^{\circ} "$.
} 
pronunciado por López de Carvajal en la misa de acción de gracias celebrada en Santiago de los Españoles a raíz de la conquista de Lorca. Los dos obispos patrocinaron representaciones, festejos y alentaron composiciones literarias. El papel influyente de ambos fue muy destacado. López de Carvajal fue también el encargado de pronunciar la Oratio pro eligendo Pontifice en la inauguración del cónclave que proclamaría a Rodrigo Borja como Papa.

Los sumarios latinos, a los que concretamente nos referimos, guardan entre sí una estrecha relación. Aunque el contenido es el mismo, sin embargo se aprecian diferencias estilísticas que apuntan a la presencia de dos traductores a partir de un común hipotexto. Ambos ocupan una reducida extensión.

El integrado en el códice latino 461 ocupa folio y medio (273r-274v). Este sumario esté escrito a línea tirada en letra gótica redonda con influjo de la cortesana moderna. La copia se atribuye sin reservas al propio Schedel y aparece junto con otros documentos entre los que es destacable la serie de discursos pronunciados ante Inocencio VIII por los embajadores de los príncipes cristianos en 1490, según reza su incipit $^{26}$. Entre los oradores hay que incluir al ya citado obispo de Cesena y los mencionados obispos de Badajoz y Astorga. En la mayoría de aquellos discursos, son frecuentes las alusiones a la contienda granadina y a la labor de los cristianísimos reyes hispanos, alusiones muy a tono con el motivo de la convocatoria.

El segundo sumario recogido en una miscelánea de documentos, ocupa los folios 44r-45r del Clm 14053 y está escrito a doble columna en letra bastarda.

Como hemos apuntado, las diferencias de carácter estilístico entre ambos, confirman la presencia de varios traductores a partir de un texto común. Es de suponer que los citados obispos españoles recibieron los informes en castellano como ocurrió con la carta de López de Haro conservada en Roma en su versión original castellana.

\section{LOS INCUNABLES FRANCESES Y LA ACTIVIDAD DE LOS EMBAJADORES ESPAÑOLES}

A partir de un hipotexto común, pasando en algunos casos por la correspondiente versión latina, como las contenidas en los sumarios, se vierten a lenguas diferentes las noticias oficiales llegadas a Roma. Estas traducciones se nos han transmitido recogidas en incunables.

Tratándose de la versión italiana, en el Gesamtkatalog der Wiegedrücke se recogen también cuatro incunables impresos en diferentes puntos de Italia entre 1492 y 1500 . Entre ellos hay coincidencia en el contenido, y todos aparecen bajo el título de Storia di Granata. Es frecuente que concluyan con la expresión: crescha la sancta fede del baptesmo, que insinúa el interés por

\footnotetext{
${ }^{26}$ Conventio Oratorum regum ... facta Romae pro expeditione contra Turcos ad petitionem Innocentii Octavii. Anno Domini MCCCCLXXXX.
} 
destacar la relación entre el caso granadino y los turcos. El planteamiento de estas ediciones responde a la perspectiva italiana y centroeuropea.

En el caso de la traducción francesa, se conservan dos incunables ${ }^{27}$ en la Bibliothèque nationale de France $(\mathrm{BnF})$. Durante algún tiempo se creyó que existía un ejemplar de esta edición en la Biblioteca del Hospital Real de Granada. Así lo señalaba Palau. Hoy se sabe que se trata de un facsímil del s. XIX.

De los dos incunables de la Bibliothèque national de France, el primero fue impreso por Jean Tréperel entre marzo de 1492 y mayo de 1493 en París. El segundo, atribuida su impresión a Guillaume Le Rouge, después de marzo de 1492, tal vez, en la ciudad de Troyes. Ambos presentan una tipografía gótica a línea tirada y van precedidos de una xilografía. En el primer caso se trata de la marca del impresor, reutilizada por Jean Petit. En la xilografía del segundo se representa una escena palaciega con varios personajes. Es posible que también en este caso estemos ante la reutilización de una misma tabla, lo que no debe extrañarnos dada la premura con la que se llevó a cabo todo el procedimiento. En cualquier caso, en sendas ediciones se trasluce cierto interés por el acabado final.

Independientemente del interés que puedan despertar ambos ejemplares desde un punto de vista tipográfico o de historia del libro, el texto francés común a los dos es especialmente valioso para conocer la manera como se llevó a cabo desde Roma toda una política de difusión y propaganda de los hechos relacionados con la monarquía española. El texto hace referencia al procedimiento seguido en la divulgación del triunfo granadino pero tal proceder se puede trasladar de manera general a situaciones y acontecimientos relacionados también con el suceso. En aquel proceder participaron de manera principal los embajadores españoles López de Carvajal y Ruiz de Medina como se cita en la información recogida en el preámbulo y en la apostilla final. En ambos casos el traductor francés dice textualmente:

"El sumario siguiente, redactado de manera sucinta y brevemente, contiene un resumen de lo difundido ampliamente por medio de escritos y cartas por los obispos de Badajoz y Astorga, elocuentes cronistas y embajadores de los muy nobles y muy poderosos rey y reina de España"28.

Hasta aquí la coincidencia con el incipit de los sumarios es total, pero más adelante el anónimo traductor añade nuevos datos sobre la responsabilidad de los obispos de Badajoz y Astorga, embajadores de los Reyes Católicos en Roma como se ha dicho, en el proceso de difusión y su finalidad:

"Dichas misivas dirigidas y enviadas por los citados embajadores a diversos reinos y estados, así como a la Santa Sede Apostólica, contienen la feliz victoria obtenida hace tres meses por el citado rey. (...) Las últimas

\footnotetext{
${ }^{27} \mathrm{Se}$ corresponden en el Gesamtkatalog der Wiegedrücke con las signaturas GW 11292 y GW 11293. La edición diplomática del texto francés fue realizada por Georges HAMEL, Un incunable français relatif a la prise de Grenade, "Revue Hispanique", 36 (1916), pp. 159-169. Este autor menciona otro incunable en la Biblioteca de la Universidad de Granada, pero en realidad se trata de un fácsimil del s. XIX.

${ }^{28} \mathrm{GW} 11292$, ff. A2 r - v. G. HAMEL, o. c. p. 160-161.
} 
misivas de los citados embajadores han sido escritas en dicho lugar de Granada el décimo día de enero pasado, y el sumario de todas estas cartas ha sido mandado por los citados embajadores y obispos redactado brevemente y traducido al latín por veinte de sus secretarios. De esta recopilación procede la traducción en francés de la manera más fiel que haya sabido y podido"29.

En una postilla final, la versión francesa confirma de manera explícita la finalidad que se perseguía con la divulgación de aquellos acontecimientos:

"Estos acontecimientos han sido brevemente contados y enviados a varios reinos y estados con el fin de que cualquiera conozca la victoria del noble rey de España y para que sea alabado y se dé gracias a Dios creador".

Aunque el traductor francés menciona la labor de veinte secretarios como autores de la versión latina, tal vez se trate de una sola versión y veinte copistas. En cualquier caso, López de Carvajal con ocasión de la Epistola consolatoria in obitu Johannis Hispaniae principis contó con su secretario García Bovadilla como traductor al latín ${ }^{30}$; de la misma manera, cabe la posibilidad de que el autor de la Historia Baetica, Carlo Verardi, pudo también haber participado en la traducción latina dada la información precisa y directa que se intuye en el texto del drama, su estrecho contacto con los españoles, y sus funciones como cubiculario y secretario de cartas latinas del Papa.

Podríamos concluir, por tanto, señalando que el objetivo perseguido con la divulgación de los acontecimientos granadinos habría que situarlo en la perspectiva de los intereses españoles. No se trataba de la cuestión turca, como en el caso de Centro-Europa o, en parte, de Italia; se buscaba, ante todo, potenciar la imagen de un soberano, del rey Fernando II, la cual creció de tal manera que, al decir de algunos, hizo que las tierras se duplicasen al otro lado del Océano. Sin duda forjar esa imagen fue tarea de sus hábiles embajadores, Bernardino López de Carvajal y Juan Ruiz de Medina, quienes situados en Roma, caput Mundi, percibieron las posibilidades de captación y propaganda que implicaba la divulgación de la victoria sobre los musulmanes españoles en una Europa amenazada por el avance de los turcos, y con eficacia hicieron revertir toda aquella actividad en la exaltación de la monarquía española.

Fecha de recepción del artículo: marzo de 2010.

Fecha de aceptación y versión final: junio de 2010.

\footnotetext{
${ }^{29} \mathrm{GW} 11292$, f. [A6v]. G. HAMEL, o. c. p. 169.

${ }^{30}$ Pilar SAQUERO SUÁREZ-SOMONTE, Tomás GONZÁlEZ Rolán, Un importante texto político y literario de finales del siglo XV todavía inédito: la Epístola consolatoria a los Reyes Católicos del extremeño Bernardo López de Carvajal (prologada y traducida al latín por García de Bovadilla), "Cuadernos de fílología clásica: Estudios latinos", 16 (1999), pp. 247-277.
} 